\title{
Designing a model to improve first year student adjustment to university
}

\author{
Nasrin Nikfal Azar and Hamideh Reshadatjoo*
}

Department of Higher Education Management, College of Management and Economics, Tehran Science and Research Branch, Islamic Azad University, Tehran, Iran

\section{H R O N I C L E}

Article history:

Received July 28, 2013

Accepted 14 January 2014

Available online

March 82014

Keywords:

Adjustment

Academic self-efficacy

Academic motivation

Student satisfaction

\begin{abstract}
A B S T R A C T
The increase in the number of universities for the last decade in Iran increases the need for higher education institutions to manage their enrollment, more effectively. The purpose of this study is to design a model to improve the first year university student adjustment by examining the effects of academic self-efficacy, academic motivation, satisfaction, high school GPA and demographic variables on student's adjustment to university. The study selects a sample of 357 students out of 4585 bachelor first year student who were enrolled in different programs. Three questionnaires were used for collection of data for this study, namely academic self-efficacy, academic motivation and student satisfaction with university. Structural equation modeling was employed using AMOS version7.16 to test the adequacy of the hypothesized model. Inclusion of additional relationship in the initial model improved the goodness indices considerably. The results suggest that academic self-efficacy were related positively to adjustment, both directly $(\mathrm{B}=0.35)$ and indirectly through student satisfaction $(\mathrm{B}=0.14)$ and academic motivation $(B=0.9)$. The results indicate a need to develop programs that effectively promote the selfefficacy of first year student of student to increase college adjustment and consequently retention rate.
\end{abstract}

\section{Introduction}

A good first year transition encompasses independent functioning including the capability to be involved with a new and complex world. Therefore, it is essential to learn more about the factors influencing on new students adjustment to college. Some studies indicate that the first two years in college are very critical for student retention. For instance, $25 \%$ of college students dropped out of school after their first year (Mallinckrodt \& Sedlacek, 2009; Tinto, 1993; Tinto et al., 1994), and among all dropouts, 75\% left college during the first two years (Tinto, 1987, 1988). Research showed that this failure was because of adjustment difficulties (Tinto, 1993; Martin Jr. et al., 1999). In fact, the better-adjusted students are in academic environment, the better will be their academic performance (Lent et al., 2004).

\section{Literature review}

*Corresponding author.

E-mail addresses: h.reshadatjo@gmail.com (H. Reshadatjoo) 
There are various factors influencing a college freshman's adjustment process and this paper looks at some of factors according to adjustment theories. Most educational researchers have viewed adjustment to college as an important outcome in its own right. They have examined various factors as possible predictors of student's adjustment to college environment including demographic information (e.g., Mcdonald \& Varana, 2007), personality traits and core self- evaluations (e.g., Aspinwall \& Taylor, 1992; Becker, 2008), coping styles (e.g., Jantzer, 2006; Matthews, 1998), social support (e.g., Schneider \& Ward, 2003) and student-parent relationships (e.g., Hickman \& Andrews, 2003; Schultheiss \& Blustein, 1994). Others have examined whether students' level of adjustment to college could be the predictor of other essential educational outcomes primarily academic performance (i.e., grade and college retention (e.g., Baker \& Siryk, 1986).

Russell and Petrie (1992) explained an additional area of importance when considering the theory of adjustment to college, individual/personal factors. They considered some personal factors in addition to previous studies (Pascarella \& Terenzini, 1991; Astin, 1975, Bean, 1980, 1982) by going beyond social, academic and institutional factors to consider the role of individual factors in student's adjustment to college and ultimately their persistence towards their graduation. For the purpose of this study, the conceptualization of college student adjustment will fit within the Russell and Petrie (1992) theory.

If there is a priori hypothesis, Structural Equation Modeling (SEM) could be implemented in research reliably for testing the relationships of various variables and stated that causality could not be inferred (Violato \& Hecker, 2007; Kline, 2011). The foundation of a good SEM analysis is a well-founded theatrical basis for relationship being investigated in the model (Violato \& Hecker 2007; Keline, 2011). The proposed study of this paper considers various hypotheses, including the directionality of relationships, well-founded in an adjustment literature. The variables we used in our SEM analysis were Academic Motivation (Instrinsic, Extrinsic and Amotivation), Academic Self- efficacy, Satisfaction with university (academic service, student service and campus climate) of first year student of under study university (See Fig.1).

Academic Self-efficacy is associated with individuals' convictions performed given academic tasks at designated levels (Schunk, 1991). Academic Motivation is another term related to motivation within an academic setting. Academic motivation can create confidence in one's capability, along with a desire to learn and value education (Deci et al., 1991). Student satisfaction in the context of education is associated with the favorability of a student's subjective evaluations in terms of different outcomes and educational experiences (Oliver, 1989).

The proposed study of this paper adds to the existing literature on this aspect among Iranian universities and other higher education institutions. The proposed hypotheses of this study are as follow: (a) Academic selfefficacy has direct effect on first year college student adjustment. (b) academic motivation has direct effect on first year student adjustment. (c) satisfaction with university has direct effect on first year student adjustment.(d) high school GPA has direct effect on first year student adjustment. (e) demographic variables have effect on student adjustment.

\section{Research Methodology}

\subsection{Sample}

The sample of the present study comprises of 300 first year students of Azad University, located in Tehran, who were selected using random sampling method in academic over the period 2012-2013. The thumb rule for a good sample size for SEM is more than 200 and our sample size satisfied both rules (Violato \& Hecker, 2007; Kline, 2011).

\subsection{Instruments}


The instruments used in this study were adapted from well-established instruments and the items for each instruments were validated by experts. The instruments used are as follows:

\subsubsection{The Academic Motivation Scale}

According to Vallerand et al. (1992, 1993), Cronbach's alphas changes from 0.63 to 0.86 for similar studies accomplished using the questionnaire of AMS-C. The AMS-C is a 28-item questionnaire designed to ascertain student's reasons for attending college (Vallerand et al., 1992). Student's rating on a 1-7 point scale indicated how closely they believed the item described their motives for pursuing postsecondary education. A motivation score was calculated for each category (intrinsic, extrinsic and motivation) by averaging the score of all items in the subscales within the category. In present study Alpha for Academic motivation scale was 0.862 .

\subsection{The College Academic Self-Efficacy Scale}

This scale was completed as a measure of academic self-efficacy (CASE; Owen \& Froman, 1988) described by Bandura's (1997) foundational theory. The scale consists of 33 self-report items that are scored on a 5-poing Likert-type scale ranging from $1=$ very little to $5=$ quite a lot. The scale yields a total score that is derived from the mean of the items answered. Three primary factors emerge within CASE: "(1) Social Situations,(2) Cognitive Operations, (3) Technical Skills" (Owen \&Forman,1988).

\subsubsection{The Student Satisfaction inventory}

Schreiner and Jullerat (1993) developed this questionnaire and the items are phrased as positive expectations that the institution may or may not meet (for instance, "Most students feel a sense of belonging here"). In this study, we have reduced the number of items to 47 during the process of localization. Students were asked to rate their level of satisfaction that the institution has met this expectation, using seven-point response scale from very dissatisfied (1) to very satisfied (7). Reliability of the SSI, with internal consistency of alpha $=0.98$ and three week test-retest $r=0.87$. Construct validity has been adequately established and this current study adds to the predictive validity of the instrument. For the current study, Cronbach alpha were calculated for Student total Satisfaction as 0.922, and for sub scales campus climate as 0.788, for academic Service as 0.842, and finally for student Service Scale as 0.870 , respectively.

\subsubsection{Student adaptation to College Questionnaire}

The student adaptation to college questionnaire (SACQ) developed by Baker and Siryk (1986) with 67 selfreported items yielding 4 scales assessing college student's academic adjustment, social adjustment, personal/emotional adjustment, and their attachment to the university. Students responded to each statement on a 9-point scale ranging from 1= "applies very closely to me" to 9 = "Doesn't apply to me at all" and high scores indicate better adjustment. Alpha coefficient for the full scale and the subscales ranged from 0.81 to 0.95 among first year university students (Baker \& Siryk, 1986). The instrument reliability levels were tested and findings revealed that the alpha values for the variables for overall adjustment scale was 0.865 , for social adjustment scale was 0.816 , for academic adjustment scale was 0.602 , for institutional attachment scale was 0.780 and finally for personal-emotional scale was calculated as 0.792 , respectively. Furthermore, all the negatively worded items in above mentioned questionnaires have been reversed scored.

\section{Method of analyzing data}

The software program SPSS version 15.0 was used for our basic analysis. After checking for normal distribution of the data, linearity of relationships between variables and computing the basic correlations between the different variables, reliability tests for all the scales used to measure the different variables were performed. Multiple regression analysis was planned to determine whether study dependent variables affect independent variables. 
Structural Equation Modeling (SEM) analysis was carried out using the software AMOS version 5.0. A value of the normed chi-square between 1 and 3 indicates that the proposed model was an adequate presentation of the entire set of relationships. The RMSEA considers the fit of the model to the population covariance/correlation matrix. A value of RMSEA less than 0.08 or 0.10 represent a good or a reasonable approximation respectively (Lopez et al., 2005).The CFI and NFI trace the relative improvement of the assessed model over a null where all observed variables are assumed to be uncorrelated. The CFI and NFI range from zero to 1.00, with values over 0.90 indicating a well-fitting model (Hair et al., 1995).

\subsection{Conceptual framework}

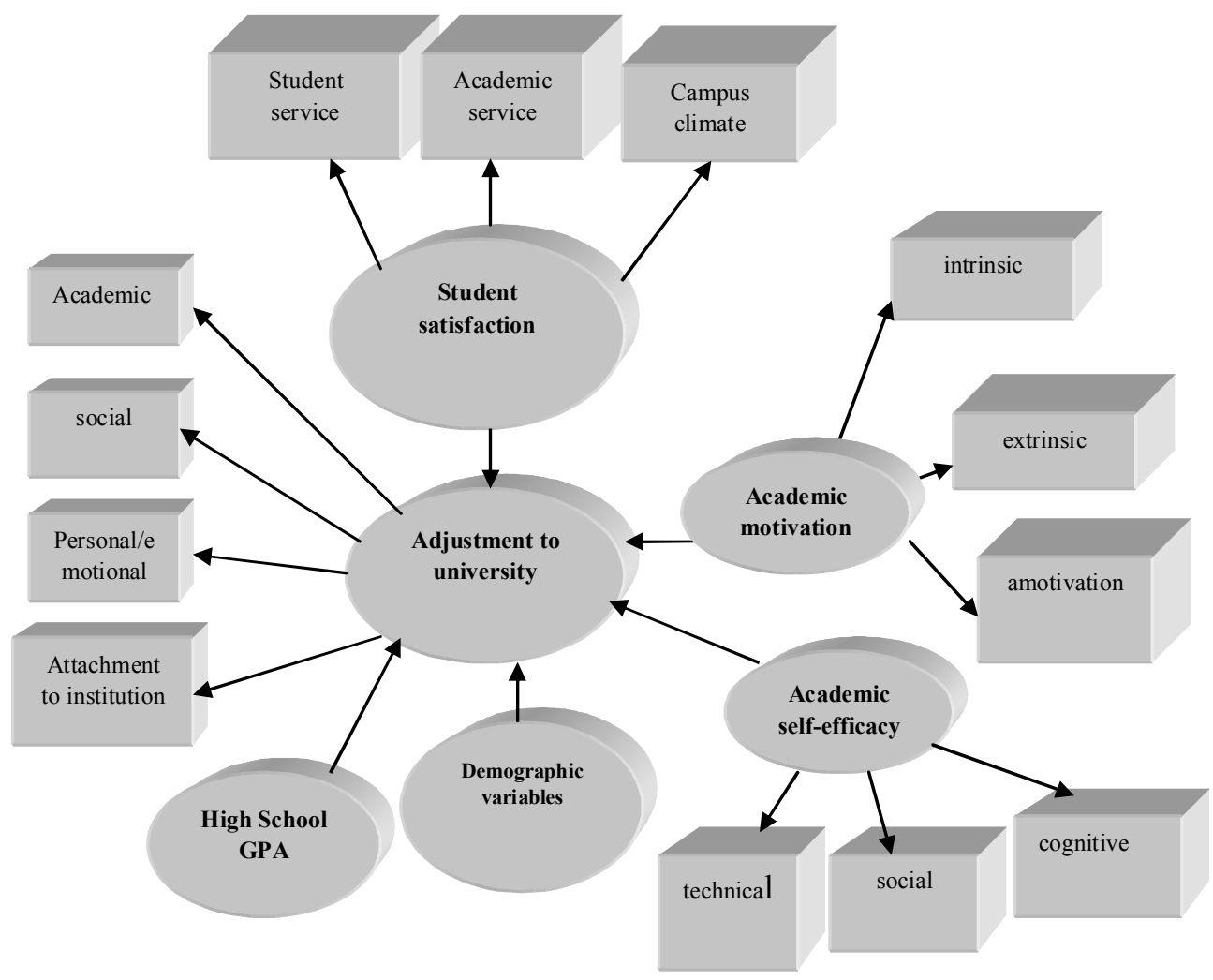

Fig. 1. Conceptual model of first year student adjustment to university, derived from Russell and Petrie theory (1992)

\section{Results}

The data were analyzed using correlation and regression analysis by the method of structural equation modeling. The co-relational analysis was applied to test the assumption whether there is a statistical relationship between the independent variables and first year student adjustment to university. The response rate of the students was $\% 100$, which included $\% 26.7$ males and $\% 73.3$ females. The gender distribution was almost the same as compared to that in the normal student population of university under study. The mean age for both males and females was 20.35.Table 1 presents the means, standard deviations, and zero-order correlations for the observed variables. Because female students were overrepresented in our sample, we analyzed for gender effects. Participant gender was dummy coded and correlated with each of the variables. 
Table 1

Design variables

\begin{tabular}{|c|c|c|c|c|c|c|c|c|c|c|c|c|c|c|}
\hline & & 1 & 2 & 3 & 4 & 5 & 6 & 7 & 8 & 9 & 10 & 11 & 12 & 13 \\
\hline 1 & Intrinsic motivation & $.116^{*}$ & 1 & & & & & & & & & & & \\
\hline 2 & Extrinsic motivation & .025 & $.605^{* *}$ & 1 & & & & & & & & & & \\
\hline 3 & motivation & $.144^{*}$ & $.614^{* *}$ & $.407^{* *}$ & 1 & & & & & & & & & \\
\hline 4 & $\begin{array}{l}\text { Academic service } \\
\text { satisfaction }\end{array}$ & -.020 & $.324^{* *}$ & $.187^{* *}$ & $.210^{* *}$ & 1 & & & & & & & & \\
\hline 5 & Campus climate satisfaction & .001 & $.292^{* *}$ & $.135^{*}$ & $.174^{* *}$ & $.732^{* *}$ & 1 & & & & & & & \\
\hline 6 & Student service satisfaction & -.070 & $.250^{* *}$ & $.156^{* *}$ & $.194^{* *}$ & $.748^{* *}$ & $.602^{* *}$ & 1 & & & & & & \\
\hline 7 & Self-efficacy(social) & -0.095 & $0.212 *$ & $0.230 *$ & $0.172 *$ & $0.161^{*}$ & $0.212 *$ & 0.083 & 1 & & & & & \\
\hline 8 & Self-efficacy(conceptual) & -0.034 & $0.454^{*}$ & $0.281^{*}$ & $0.325^{*}$ & $0.319^{*}$ & $0.336^{*}$ & $0.221^{*}$ & $0.499^{*}$ & 1 & & & & \\
\hline 9 & self-efficacy(technical) & -0.067 & $0.338^{* *}$ & $0.244 * *$ & $0.276^{* *}$ & $0.338^{* *}$ & $0.354^{* *}$ & $0.250^{* *}$ & $0.611^{* *}$ & $0.711^{* *}$ & 1 & & & \\
\hline 10 & Academic adjustment & .039 & $.468^{* *}$ & $.264^{* *}$ & $.427^{* *}$ & $.520^{* *}$ & $.558^{* *}$ & $.380^{* *}$ & $0.299^{* *}$ & $0.540^{* *}$ & $0.534 *$ & 1 & & \\
\hline 11 & Social adjustment & -.049 & $.355^{* *}$ & $.226^{* *}$ & $.340^{* *}$ & $.400^{* *}$ & $.472^{* *}$ & $.375^{* *}$ & $0.286^{* *}$ & 0.466 & 0.367 & 0.635 & 1 & \\
\hline 12 & $\begin{array}{l}\text { Personal-emotional } \\
\text { adjustment }\end{array}$ & -.031 & $.200^{* *}$ & .023 & $.290^{* *}$ & $.313^{* *}$ & $.323^{* *}$ & $.280^{* *}$ & 0.055 & 0.300 & $0.285^{* *}$ & $0.530^{* *}$ & $.480^{* *}$ & 1 \\
\hline 13 & Attachment to university & .015 & $.355^{* *}$ & $.208^{* *}$ & $.478^{* *}$ & $.321^{* *}$ & $.360^{* *}$ & $.281^{* *}$ & $0.212 * *$ & $0.454^{* *}$ & $0.338 * *$ & $0.666^{* *}$ & $.766^{* *}$ & $.510^{* *}$ \\
\hline & $\mathrm{M}$ & 20.35 & 4.67 & 5.21 & 5.33 & 2.76 & 2.65 & 2.71 & 2.93 & 3.43 & 3.21 & 5.35 & 5.63 & 5.57 \\
\hline & SD & 3.271 & 1.284 & 1.245 & 1.692 & 0.609 & 0.611 & 0.617 & 0.834 & 0.577 & 0.589 & 1.064 & 1.251 & 1.457 \\
\hline
\end{tabular}

\subsection{Structural Equation Modeling}

Structural equation modeling is particularly well suited to these analysis, because exogenous and endogenous variables of the study can be considered latent constructs that are imperfectly measured by questionnaire items (or indexes derived from them) and (2) structural equation modeling, as a multivariate method, allows estimation of cross-equation error correlation (see Bollen, 1989).

The first result of structural equation modeling revealed a poor fit of proposed model (fit indices were ChiSquare $=346.542, \mathrm{RMSEA}=0.124, \mathrm{IFI}=0.865, \mathrm{CFI}=0.864, \mathrm{P}<0.001$ ). After checking the improved modification indices, three indirect paths were added to the model. As shown in Fig. 2, academic motivation mediated between academic self-efficacy and adjustment, and satisfaction mediated academic self-efficacy an adjustment.

Based on the second structural equation modeling results after addition of new paths, the model indicated a relatively good fit between the data and the model. Fig. 2 presents the statistics of a graphic depiction of the full structural equation, suggest that improved model possesses a satisfactory degree of fit with the data (Normed Chi-Square $=229.323$, RMSEA $=0.98, \mathrm{CFI}=0.92, \mathrm{NFI}=0.9, \mathrm{P}<0.001$ ). Furthermore, all the estimated standardized coefficients are statistically significant and their values in most cases are high enough.

Table 2

Model Fit Indexes

\begin{tabular}{llll}
\hline Fint Indexes for first model & & \multicolumn{2}{l}{ Fint Indexes for improved model } \\
\hline 229.323 & $\mathrm{X} 2$ & 346.542 & $\mathrm{X} 2$ \\
0.59 & Df & 0.62 & $\mathrm{df}$ \\
$<0.001$ & $\mathrm{P}$ & $<0.001$ & $\mathrm{p}$ \\
0.893 & NNFI & 0.829 & NNFI \\
0.087 & RMR & 0.198 & RMR \\
0.098 & RMSEA & 0.124 & RMSEA \\
0.894 & NFI & 0.841 & NFI \\
0.92 & CFI & 0.864 & CFI \\
0.92 & IFI & 0.865 & IFI \\
0.893 & GFI & 0.839 & GFI \\
\hline
\end{tabular}

Turning now to the SEM specific results the significant arrows between the various variables of the model suggest the following relationships: (a) Academic self-efficacy directly influence student adjustment (coefficient standard $=0.35, \mathrm{p}<0.001$ ), (b) Academic self-efficacy indirectly influence student adjustment through student satisfaction (coefficient standard=0.14. $\mathrm{p}<0.001$ ), (c) Academic self-efficacy indirectly influence student adjustment through academic motivation (coefficient standard $=0.9, \mathrm{p}<0.001$ ). 


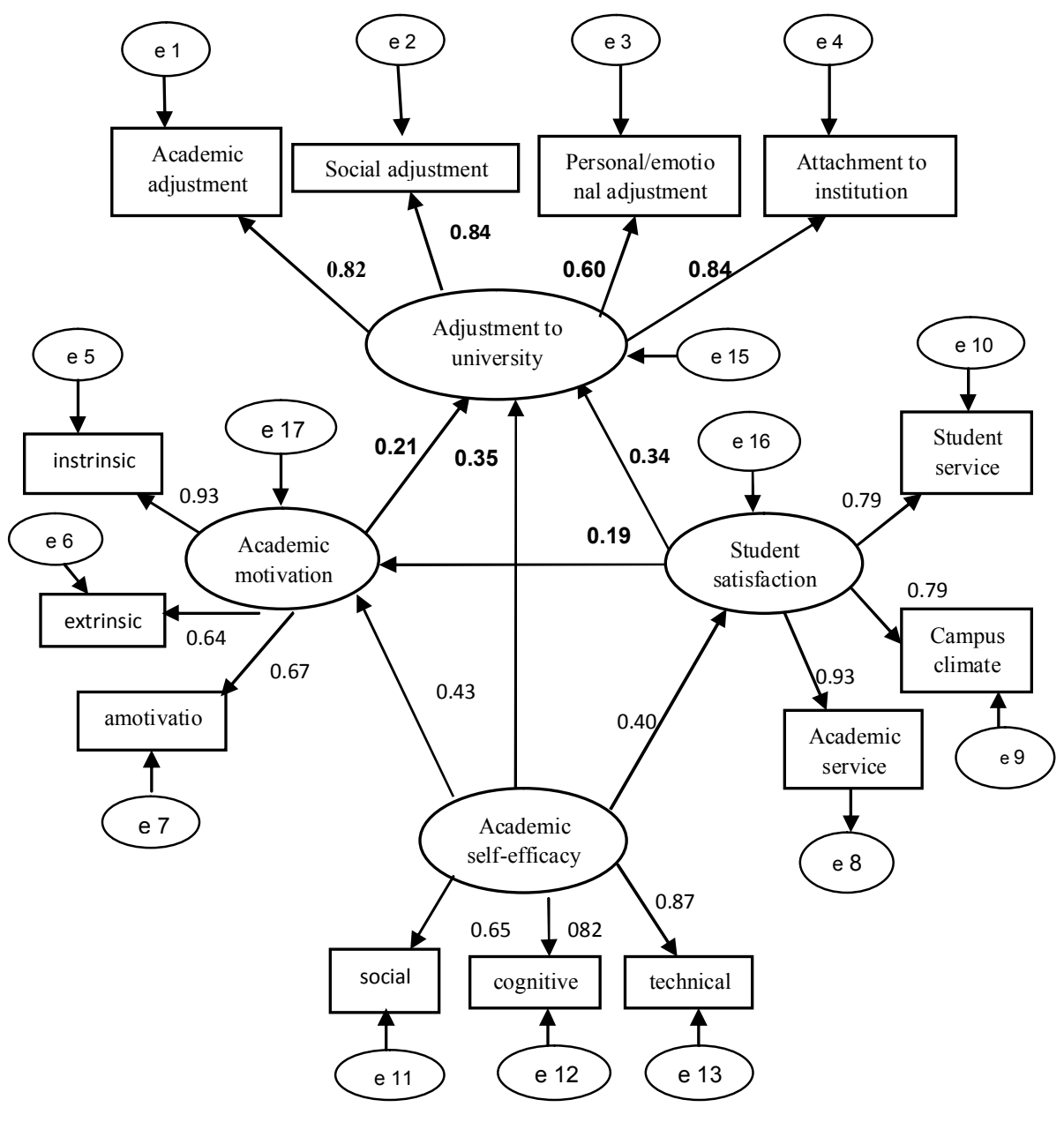

Fig. 2. Estimated Model using AMOS

Overall, the results of the structural equation modeling analysis reveal that the improved model is a good fit to the data, which suggests that academic self-efficacy play an impressive role in first year college student overall adjustment (standardized coefficient $=0.35, \mathrm{p}<0.001$ ). In addition, results suggest that academic self-efficacy is stronger predictor of first year student adjustment comparing academic motivation and student satisfaction.

Previous research has shown a relationship between academic self-efficacy and a student's adjustment to college. In addition, the finding is consistent with the finding of Lent (2004) who explored academic selfefficacy as a predictor of academic adjustment. Previous research shows a relationship between academic selfefficacy and college adjustment. Highly efficacious students entered college with confidence in their ability to perform well academically. Students who lacked self-efficacy did not perform as well academically as those students who had higher academic expectations. Self-efficacy remained significant even when controlling for the effect of high school GPA as measures of academic ability. Some people suggest that academic-self efficacy expectations could be an important factor in college persistence. Self-efficacy beliefs have been associated with motivation by determining what goals are set, how much effort is used to accomplish the goals, and the amount of time and resiliency expended during difficulties and failure (Bandura, 1993). 


\subsection{Conclusion}

In conclusion, the most positive outcome of this research have been academic that self-efficacy affects first year student overall adjustment to university both directly and indirectly through academic motivation and student satisfaction with university.

As Bandura (1997) asserted, the finding of the present study suggest that individual self-efficacy is likely to play a large role in the goals people set for themselves and how they go about accomplishing them. In essence, the experience of doing this study has fostered a great interest in pursuing more opportunities to improve first year student adjustment to university.

\section{Acknowledgment}

The authors would like to thanks the anonymous referees for constructive comments on earlier version of this paper.

\section{References}

Aspinwall, L. G., \& Taylor, S. E. (1992). Modeling cognitive adaptation: a longitudinal investigation of the impact of individual differences and coping on college adjustment and performance. Journal of personality and social psychology, 63(6), 989.

Astin, A. W. (1975). Preventing students from dropping out (pp. 297-308). San Francisco: JosseyBass.

Baker, R. W., \& Siryk, B. (1986). Exploratory intervention with a scale measuring adjustment to college. Journal of Counseling Psychology, 33(1), 31.

Bandura, A. (1993). Perceived self-efficacy in cognitive development and functioning. Educational psychologist, 28(2), 117-148.

Bandura, A. (1997). Self-efficacy: The exercise of control. Macmillan.

Bean, J. P. (1980). Dropouts and turnover: The synthesis and test of a causal model of student attrition. Research in higher education, 12(2), 155-187.

Bean, J. P. (1982). Student attrition, intentions, and confidence: Interaction effects in a path model. Research in Higher Education, 17(4), 291-320.

Becker, M. (2008). Personality and social network variables as predictors of adjustment: The transition from high school to college. ProQuest.

Bollen, K. A. (1998). Structural equation models. John Wiley \& Sons, Ltd.

Deci, E. L., Vallerand, R. J., Pelletier, L. G., \& Ryan, R. M. (1991). Motivation and education: The self-determination perspective. Educational psychologist,26(3-4), 325-346.

Hickman, G. P., \& Andrews, D. W. (2003). Humor and College Adjustment: The Predictive Nature of Humor, Academic Achievement, Authoritative Parenting Styles on the Initial Adjustment of Male and Female First-Year College Students. Journal of The First-Year Experience \& Students in Transition, 15(2), 61-81.

Jantzer, A. M. (2006). Retrospective reports of bullying victimization, college adjustment, and the role of coping. ProQuest.

Kline, R. B. (2011). Principles and practice of structural equation modeling. Guilford press.

Lent, R. W. (2004). Toward a Unifying Theoretical and Practical Perspective on Well-Being and Psychosocial Adjustment. Journal of Counseling Psychology,51(4), 482.

Perez Lopez, S., Montes Peon, J. M., \& Vazquez Ordas, C. J. (2005). Human resource practices, organizational learning and business performance.Human Resource Development International, 8(2), 147-164.

McDonald, S.D. \&Varena, S.R. (2007). Interracial social comfort and its relationship to adjustment to college. Journal of Negro Education, 76 , 130-141

Mallinckrodt, B., \& Sedlacek, W. E. (2009). Student retention and the use of campus facilities by race. NASPA Journal, 46(4), 566-572. 
Martin Jr.,W.E.,Swartz,J.L,\&Madson, M.(1999).Psychosocial factors that predict the college adjustment of first- year undergraduate students: implications for college counselors. Journal of College Counseling, 2(2), 121-133.

Matthews, T.B. (1998). The influence of parental attachment and coping style on the adjustment to college. unpublished dissertation, Syracuse University.

Oliver, R. L. (1989). Processing of the satisfaction response in consumption: a suggested framework and research propositions. Journal of Consumer Satisfaction, Dissatisfaction and Complaining Behavior, 2(1), 1-16.,

Owen, S. V., \& Froman, R. D. (1988). Development of a college academic self-efficacy scale. ERIC Clearinghouse.

Pascarella, E. T., \& Terenzini, P. T. (1991). How college affects students (pp. 3-7). K. A. Feldman (Ed.). San Francisco: Jossey-Bass.

Russell, R.K., \& Petrie, T.A. (1992). Academic adjustment of college students: Assessment and counseling. In S.D. Brown and R.W. Lent (Eds.), Handbook of Counseling Psychology ( $\left.2^{\text {nd }} E d.\right)$ (PP.485-511). New York: John Wiley and Sons.

Schneider, M. E., \& Ward, D. J. (2003). The role of ethnic identification and perceived social support in Latinos' adjustment to college. Hispanic Journal of Behavioral Sciences, 25(4), 539-554.

Schultheiss, D. E. P., \& Blustein, D. L. (1994). Role of adolescent-parent relationships in college student development and adjustment. Journal of Counseling Psychology, 41(2), 248.

Schunk, D. H. (1991). Self-efficacy and academic motivation. Educational psychologist, 26(3-4), 207-231.

Schreiner, L.A., \& Jullerat, S.L. (1993). The Student Satisfaction Inventory. Iowa City, OA: NoelLevitz

Tinto, V. (1994). Constructing Educational Communities: Increasing Retention in Challenging Circumstances. Community College Journal, 64(4), 26-29.

Tinto, V. (1993).leaving college: Rethinking the causes and cures of student attrition( $2^{\text {nd }}$ Ed.).

Tinto, V. (1987). Leaving college: Rethinking the causes and cures of student attrition.

Tinto,V. (1988). Stages of student departure: Reflections on the longitudinal character of student leaving. Journal of Higher Education,59(4),438-455.

Vallerand, R. J., Pelletier, L. G., Blais, M. R., Briere, N. M., Senecal, C., \& Vallieres, E. F. (1992). The Academic Motivation Scale: A measure of intrinsic, extrinsic, and amotivation in education. Educational and psychological measurement, 52(4), 1003-1017.

Violato,C., \& Hecker, K. G. (2007). How to use structural equation modeling in medical education research: A brief guide. Teaching and Learning in Medicine, 19(4), 362-371. 